\title{
Placement of Bioengineering and Biomedical Engineering Graduates
}

\author{
Steven Schreiner \\ Western New England College, Springfield Massachusetts
}

\begin{abstract}
This paper presents three years of data available from a survey of placement of bioengineering and biomedical engineering graduates. The source of the data is the annual Placement Survey of the Academic Council of the American Institute of Medical and Biological Engineering (AIMBE). This voluntary survey yields perhaps the most comprehensive understanding of immediate post-graduation activity for the field. This paper focuses on data for bachelor, master, and doctor-level graduates. Looking across the three years, the data appear consistent with no apparent major trends. The overall placement of bioengineering and biomedical engineering graduates has averaged $89 \%$ for the period with all three educational levels showing a slight upward trend; in the most recent survey (2004), each educational level had overall placements above $90 \%$.
\end{abstract}

\section{Introduction}

Placement of biomedical engineering students after graduation is of great interest to the biomedical engineering education community. Each university and college has a unique experience and perspective of where biomedical engineers are placed. Some programs report a large proportion going on to medical school or graduate school while others report a majority going directly to industry. Perhaps for the first time in the history of the field, definitive data exists to characterize the placement of the majority of biomedical engineering graduates across the country.

The Academic Council of the American Institute of Medical and Biological Engineering (AIMBE) has been conducting a placement survey of member institutions for several years and has recently begun to publish the results. In the past three years, the survey was successful in capturing the placement of a large cohort of graduates in the field: 1475 graduates in 2003-2004; 1334 graduates in the 2002-2003 academic year; and 808 graduates in the 2001-2002 academic year. As a result, this survey is potentially the most reliable instrument that exists to track the initial placement of graduates. Other placement and salary surveys often struggle with relatively small sample sizes. Perhaps the most comprehensive employment survey of the field of engineering is conducted by the National Science Foundation (NSF) and placed into the Scientists and Engineers Statistical Data System (SESTAT) [1]. However, the NSF SESTAT data does not look explicitly at the question of initial placement at the time of graduation.

In this paper, overall trends in placement for bioengineering and biomedical engineering are examined.

Proceedings of the 2005 American Society for Engineering Education Annual Conference \& Exposition Copyright ( 2005, American Society for Engineering Education 


\section{Methods}

Each year the Academic Council of AIMBE conducts a placement survey of its member institutions. The survey is sent via email in October to the Council contact person for each university; reminder solicitations are made as appropriate. Responses are collected via email and tallied in January of each year for initial presentation at the annual Council meeting in February.

Since each university will have various, multiple graduation dates throughout the calendar year, the survey asks respondents to include graduates from September 1 of the previous calendar year to the August 31 of the present calendar year. This time frame will therefore include fall, spring, and summer graduates. No attempt is made to qualify when the graduates were placed, although many institutions have data at the time of graduation only. One would expect that the majority of undergraduate and perhaps graduate student completions occur at the end of the spring semester.

The responding universities are both public and private and represent a range of bioengineering and biomedical engineering curricula. Some institutions have all three levels of education presented here (bachelor, master, and doctor), while others have only a subset of degree programs. The number of Academic Council members has grown over the three year period from 65 members in 2002 to 86 members in 2004; the number of schools contributing data to the survey has increased slightly with a 51\% response rate in 2004. Even though membership in the Council has grown, many new programs have recently been created and many have yet to produce graduates. It is expected that the number of contributing universities will increase over the next five years.

The data are categorized for baccalaureate, masters, and doctoral graduates and include the following major and subcategories:

1. Education
a) Engineering
b) Medicine
c) Business/Management
d) Law
e) Post-doctoral studies
f) Other

2. Employment

a) Bioengineering in industry

b) Consulting

c) Hospital

d) Government

e) Academia

f) Other

3. Seeking employment

4. Unknown

Proceedings of the 2005 American Society for Engineering Education Annual Conference \& Exposition Copyright (C) 2005, American Society for Engineering Education 
The responses from each university are summed for each category and educational level. Data for the 2003 survey is reported on the AIMBE website:

http://www.aimbe.org/news/2002_2003 empsurvey.pdf.

\section{Handling of the "Unknown" Category}

The category labeled "unknown" contains the number of students whose placement status was not known at the time of the survey. It is assumed that these students follow the same placement rates as seen in the other categories and subcategories (e.g. pursued further education, obtained a job, continue to seek employment). Therefore the percentages reported here include the unknown students distributed across the other categories.

\section{Results and discussion}

Final data for the 2002 (September 2001 - August 2002 period), 2003 (September 2002 August 2003 period), and 2004 (September 2003 - August 2004 period) are included in this report.

\section{Respondents}

Table 1 shows the number of institutions and graduates that were captured in the survey. An institution is included in this table if there was at least one graduate during the survey period.

Table 1 - Number of responding universities and number of degrees for each survey year

\begin{tabular}{|c|c|c|c|c|}
\hline Survey Year & $\begin{array}{c}\text { Universities } \\
\text { Responding }\end{array}$ & $\begin{array}{c}\text { Number of } \\
\text { Bachelors }\end{array}$ & $\begin{array}{c}\text { Number of } \\
\text { Masters }\end{array}$ & $\begin{array}{c}\text { Number of } \\
\text { Doctors }\end{array}$ \\
\hline 2002 & 30 & 445 & 223 & 112 \\
\hline 2003 & 37 & 906 & 288 & 138 \\
\hline 2004 & 44 & 974 & 318 & 151 \\
\hline
\end{tabular}

\section{Bachelor-Level Graduates}

Figure 1 shows the placement of bachelor-level graduates over the past three years. The proportion of bachelor-level graduates going on to further education or finding a job has remained fairly constant with nearly twice as many graduates going on to further education. For the three year period, an average of $56 \%$ of graduates went on to further education while approximately $31 \%$ went directly to a job. For the three year period, an average of $13 \%$ of graduates was still seeking employment. Data from the latest survey (2004) indicate that the number of those still seeking employment has fallen under $10 \%$.

Clearly more bachelor-level graduates in bioengineering and biomedical engineering are choosing graduate school over entry into the job market as an entry-level engineer. It is important to note that advanced study in both medical and graduate school require a conscious decision well before graduation in order to seek acceptance. Any students who did not apply (or were not accepted) to graduate school and who have yet to find a job would show up in the "seeking employment" category. Clearly the majority of graduates in the field of bioengineering and biomedical engineering have both the ability and desire to pursue further education. 


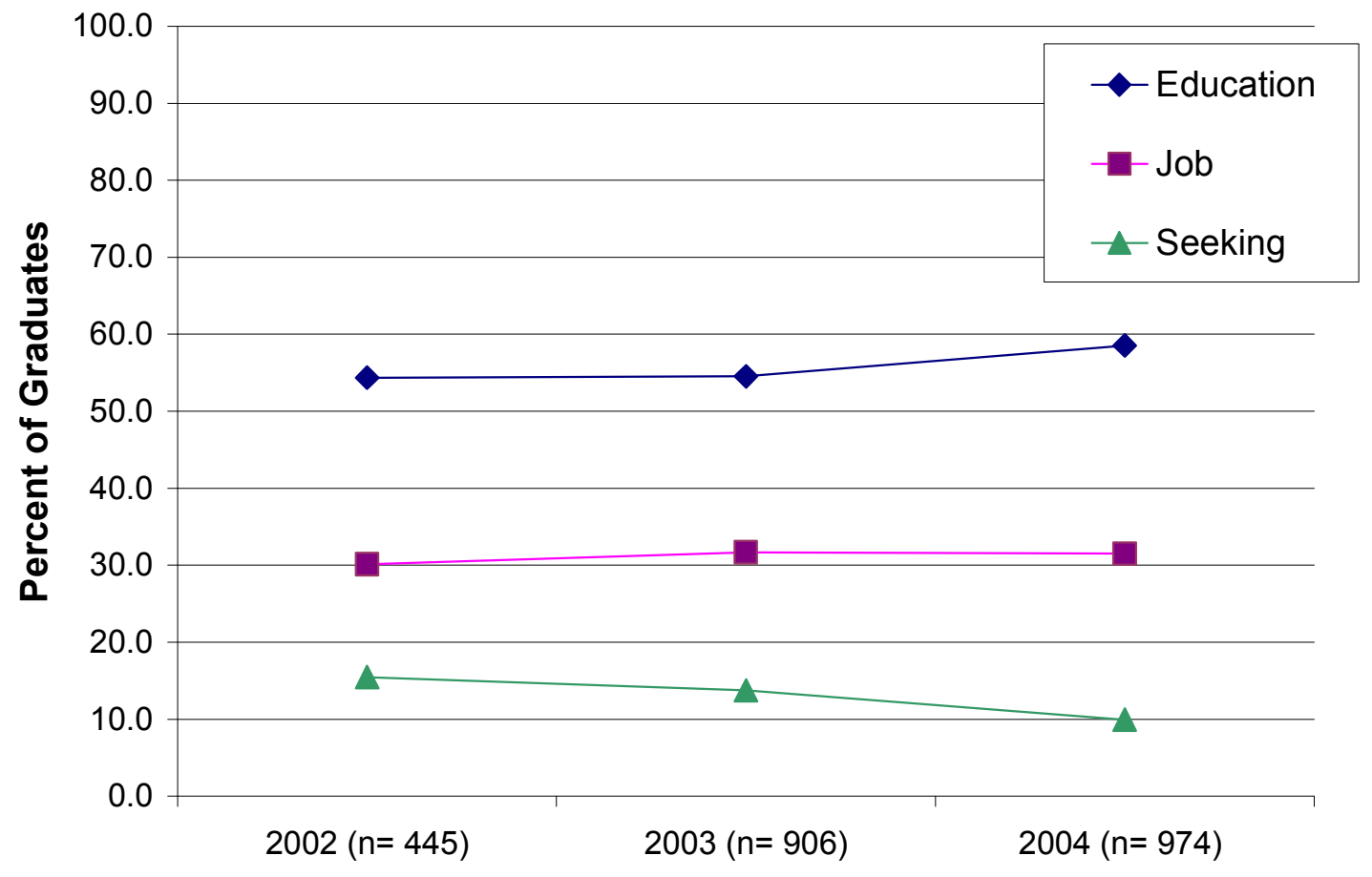

Figure 1-Bachelor-level graduate placement. 


\section{Master-Level Graduates}

Figure 2 shows the placement of master-level graduates over the past three years. The proportion of master-level graduates going on to further education or finding a job has remained fairly constant with about equal numbers of graduates going on to further education and getting a job. For the three year period, an average of $48 \%$ of graduates went on to further education while approximately $44 \%$ went directly to a job. For the three year period, an average of $8 \%$ of graduates was still seeking employment. Data from the latest survey (2004) indicate that the number of those still seeking employment has fallen to $6 \%$.

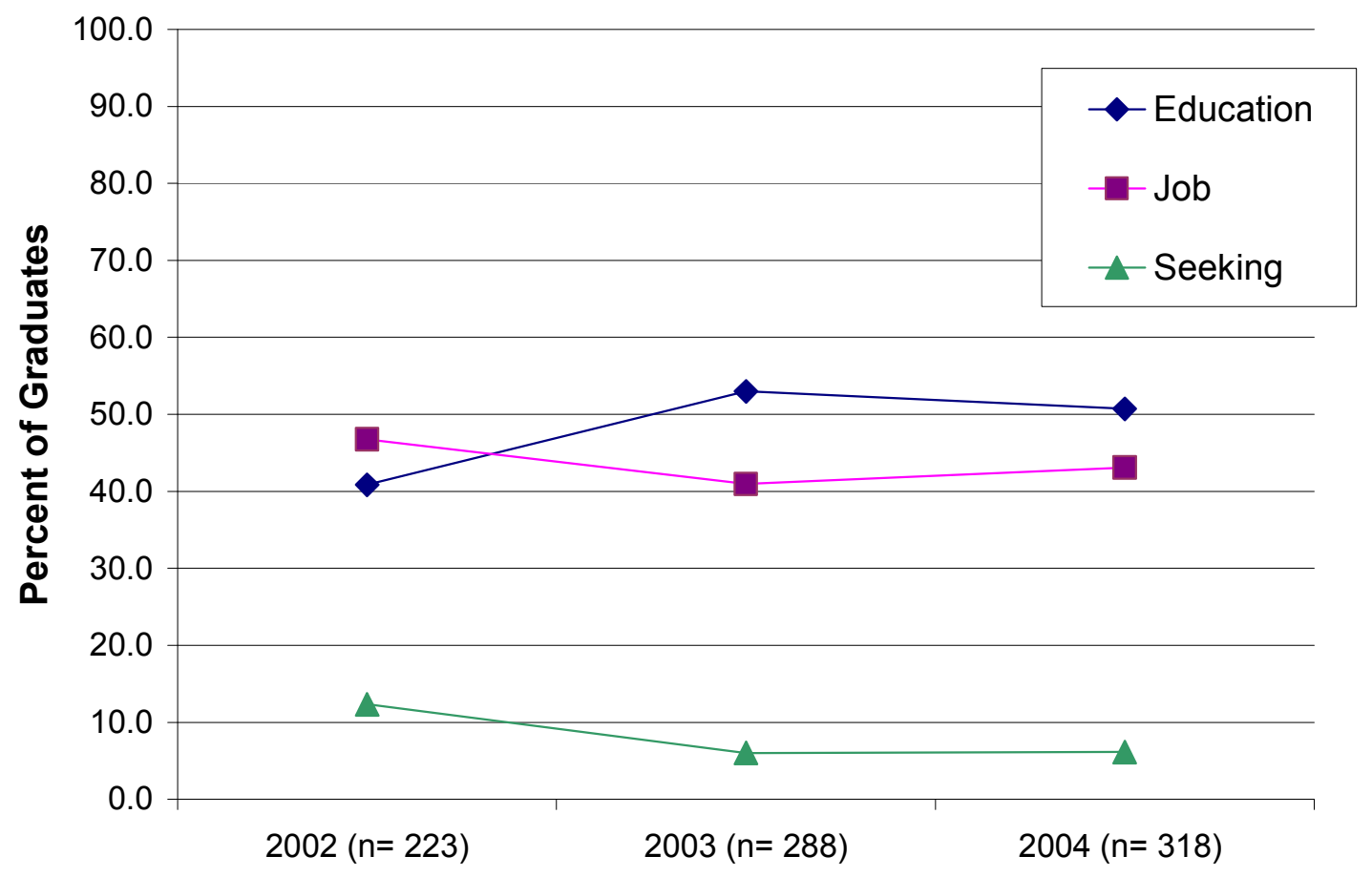

Figure 2 - Master-level graduate placement. 


\section{Doctor-Level Graduates}

Figure 3 shows the placement of doctor-level graduates over the past three years. The proportion of doctor-level graduates may have seen a shift towards further education away from going directly into the workforce. The existence of a shift is not absolutely clear, especially considering the small number of graduates each year; one graduate is just under one percent of the total for each year. For the three year period, an average of $35 \%$ of graduates went on to further education while approximately $61 \%$ went directly to a job. For the three year period, an average of $4 \%$ of graduates was still seeking employment.

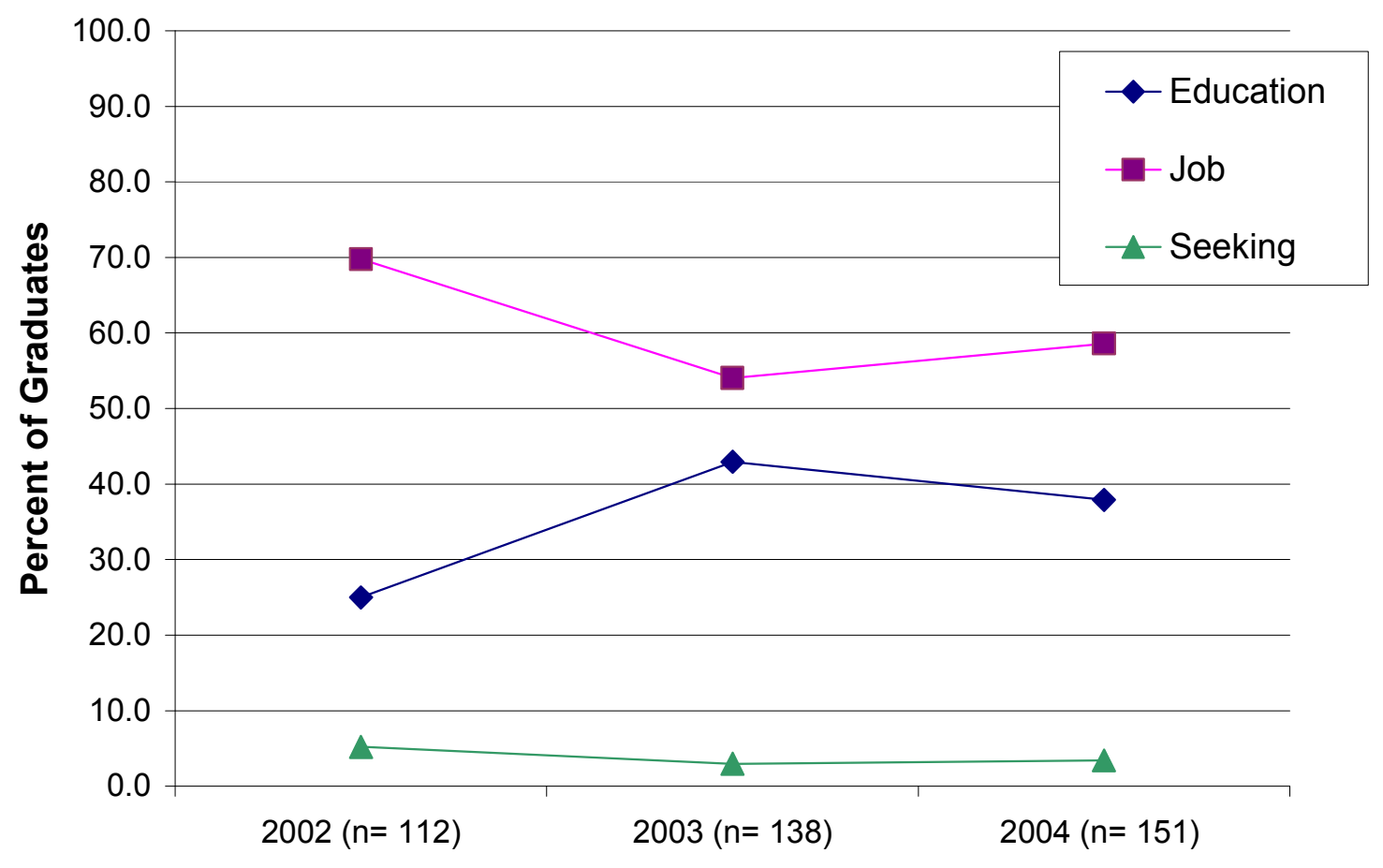

Figure 3 - Doctor-level graduate placement. 


\section{Overall Placement of Graduates}

Figure 4 shows the placement of bioengineering and biomedical engineering graduates from all levels over the past three years. For this plot, placement is calculated as the percentage of students who are either working or accepted into a program to further their education. These data include a proportion of the "unknown students" who are assumed to be distributed throughout all categories according to the proportion of students in those categories. There appears to be an increasing trend over the past three years for all three levels of education. For 2004 indicate an overall placement rate over $90 \%$.

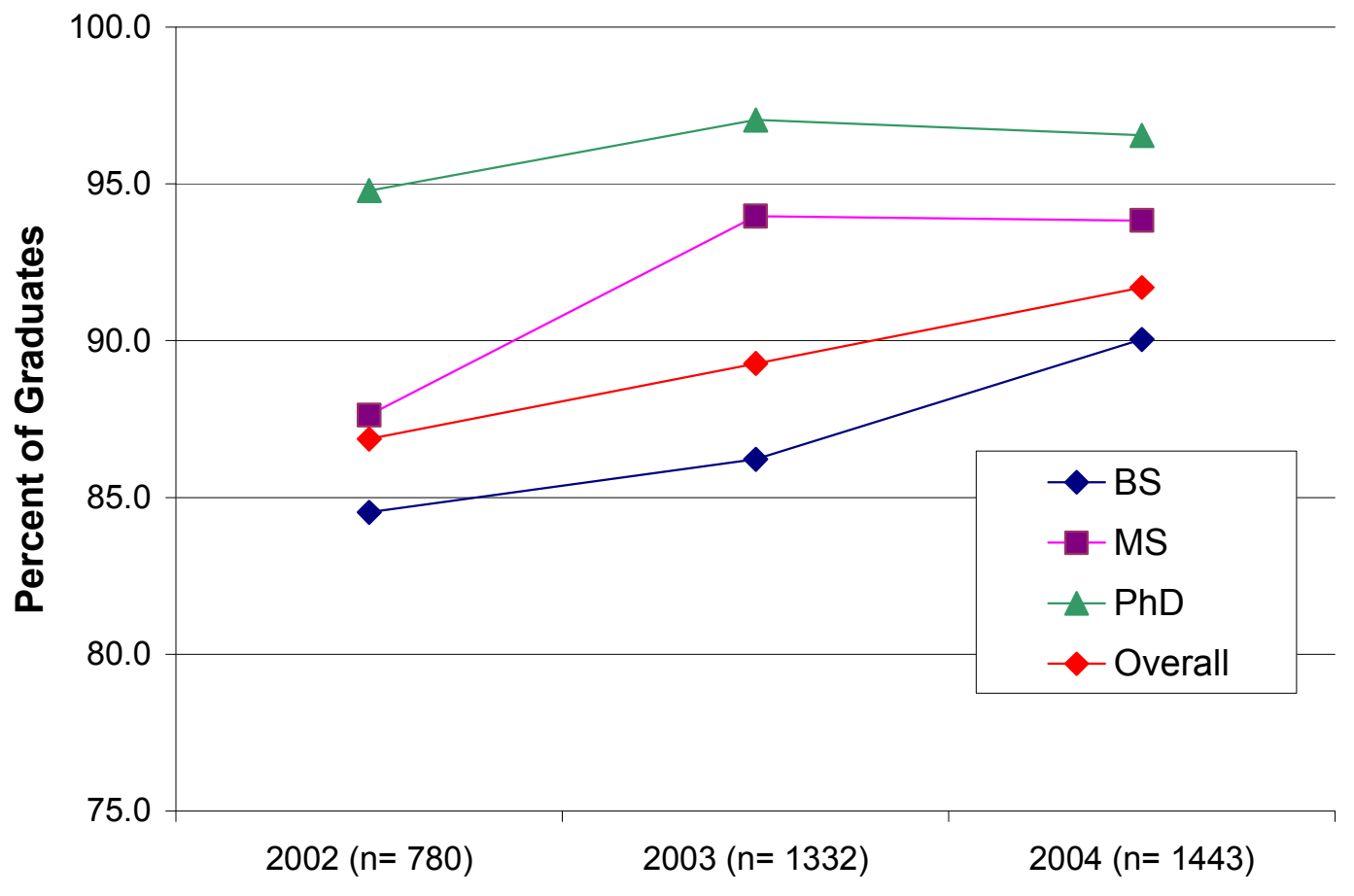

Figure 4 - Overall placement of graduates for all educational levels. 
Summary of Interesting Observations

The following observations can also be made from the data:

Note: all percentages are averaged over the three year period

- $56 \%$ of bachelor-level graduates went on to further education

- $48 \%$ of master-level graduates went on to further education

- $35 \%$ of doctor-level graduates went on to further education

- $31 \%$ of bachelor-level graduates went on to a job

- $44 \%$ of master-level graduates went on to a job

- $61 \%$ of doctor-level graduates went on to a job

- $18 \%$ of doctor-level graduates went on to a position in academia

- $18 \%$ of bachelor-level graduates went on to medical school

- $7 \%$ of master-level graduates went on to medical school

- $3 \%$ of doctor-level graduates went on to medical school

\section{Conclusion}

Analysis of the 2002- 2004 Placement Surveys of the Academic Council of the American Institute of Medical and Biological Engineering (AIMBE) indicates that the data are consistent with no major trends observed. For the three year period, an average of $56 \%$ of bachelor-level graduates went on to further education while approximately $31 \%$ went directly to a job. About equal numbers of master-level graduates went on to further education and obtained a job; an average of $48 \%$ of master-level graduates went on to further education while approximately $44 \%$ went directly to a job. An average of $35 \%$ of doctor-level graduates went on to further education while approximately $61 \%$ went directly to a job; only $18 \%$ of doctor-level graduates went on to an academic position.

The overall placement of bioengineering and biomedical engineering graduates is very good with an average placement rate of $89 \%$ for the three year period with an increasing trend; in the most recent survey (2004), each educational level had overall placements above $90 \%$.

\section{References}

[1] Kannankutty, Nirmala and R. Keith Wilkinson. SESTAT: A Tool for Studying Scientists and Engineers in the United States, National Science Foundation, Division of Science Resources Studies, NSF 99-337, April 1999.

\section{Biographical Information}

\section{STEVEN SCHREINER}

Steven Schreiner is an Associate Professor and Chairman of Biomedical Engineering Department at Western New England College in Springfield, Massachusetts. Dr. Schreiner received his Ph.D. and M.S.B.E at Vanderbilt University, and his B.S.E.E. at Western New England College. He held a postdoctoral research position in Neurosurgery at Vanderbilt University and he held a two-year National Institutes of Health (NIH) postdoctoral fellowship at Johns Hopkins University. He has held engineering positions in industry and is a Registered 
Professional Engineer in Tennessee. His interests include engineering education, advanced surgical navigation devices, medical instrumentation, and medical imaging. He has been coordinating the AIMBE Placement Survey for three years. 